\title{
Laparoscopic spleen preserving distal pancreatectomy
}

\author{
Ho-Seong Han, Yoo-Seok Yoon, Seong Uk Kwon, Jai Young Cho, YoungRok Choi, Jae Seong Jang \\ Department of Surgery, Seoul National University Bundang Hospital, Seoul National University College of Medicine, Sungnam, Korea \\ Correspondence to: Seong Uk Kwon. Department of Surgery, Seoul National University Bundang Hospital, Seoul National University College of \\ Medicine, Sungnam, Korea. Email: kwonryuk@gmail.com.
}

\begin{abstract}
Minimal invasive surgery is growing rapidly in vast fields of abdominal surgery. Nowadays, due to the development of laparoscopic instruments and improvement of surgical technique, laparoscopic pancreas surgery is becoming more widely adopted. Laparoscopic distal pancreatectomy has now become a standard procedure for the benign or borderline malignant tumor located in body or tail of pancreas, but laparoscopic spleen and splenic vessel preserving distal pancreatectomy is still a technically demanded operation. In this multimedia article, we will demonstrate our technique of laparoscopic spleen and splenic vessel preserving distal pancreatectomy.
\end{abstract}

Keywords: Spleen and splenic vessel preserving distal pancreatectomy; minimal invasive pancreatic surgery; laparoscopy

Received: 28 July 2016; Accepted: 11 August 2016; Published: 23 August 2016. doi: 10.21037 /jovs.2016.08.03

View this article at: http://dx.doi.org/10.21037/jovs.2016.08.03

\section{Introduction}

Minimal invasive surgery is growing rapidly in vast fields of abdominal surgery. Nowadays, due to the development of laparoscopic instruments and improvement of surgical technique, laparoscopic pancreas surgery is becoming more widely adopted $(1,2)$. Laparoscopic distal pancreatectomy has now become a standard procedure for the benign or borderline malignant tumor located in body or tail of pancreas (3-6). Splenic preservation is associated with a reduction in perioperative infectious complications $(7,8)$, postoperative pancreatic fistula (9), and cancer recurrence (10,11). Therefore, in patients with benign or borderline malignant tumor in the body or tail of pancreas, spleen preserving distal pancreatectomy is preferred over combined splenectomy (12). Laparoscopic spleen and splenic vessel preserving distal pancreatectomy is still technically demanded operation (13). In this multimedia article, we will demonstrate our technique of laparoscopic spleen and splenic vessel preserving distal pancreatectomy.

\section{Patient selection and work up}

The patient is a 30 -year-old female who has a $2 \mathrm{~cm}$ mass at the pancreas body. Pancreatic tumor was detected with the abdominal sonography for health checkup. The patient does not have any symptoms. CT showed a $2 \mathrm{~cm}$ subtle low attenuating lesion at the pancreas body-tail junction, and MRI showed a $1.9 \mathrm{~cm}$ well-demarcated low signal intensity tumor in the $\mathrm{T} 1$ weighted image, intermediate high signal intensity in the T2 weighted image. Laparoscopic spleen and splenic vessel preserving distal pancreatectomy was planned.

\section{Equipment preference card}

The equipment used in our hospital includes HD dual monitors with Endoeye Flex 3D articulating Videoscope $\left(\right.$ Olympus $\left.^{\circledR}\right)$. We used The ECHELON FLEX ${ }^{\mathrm{TM}}$ Powered vascular stapler with Gold cartridge $\left(\right.$ Ethicon $\left.^{\circledR}\right)$, and LigaSure energy device $\left(\right.$ Covidien $\left.^{\circledR}\right)$.

\section{Procedure}

Under general anesthesia, patient was positioned supine. We are using four ports: one $12-\mathrm{mm}$ optical port at the umbilicus, two ports in the right abdomen. An additional 


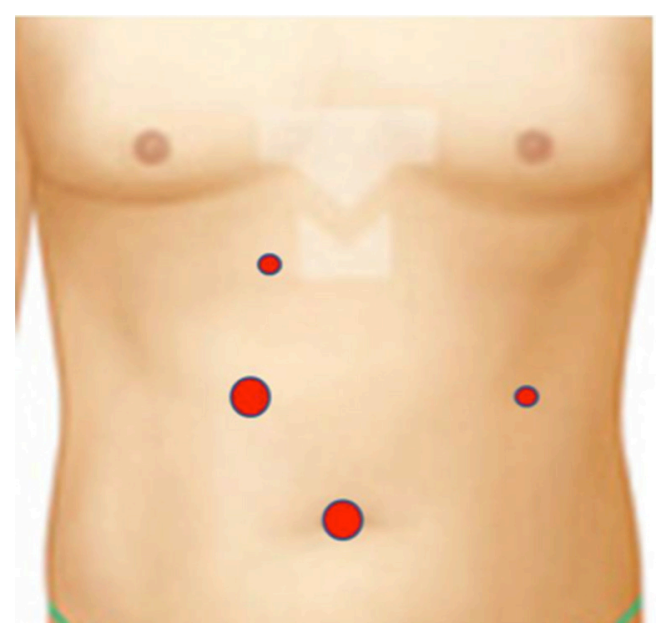

Figure 1 Trocar position.

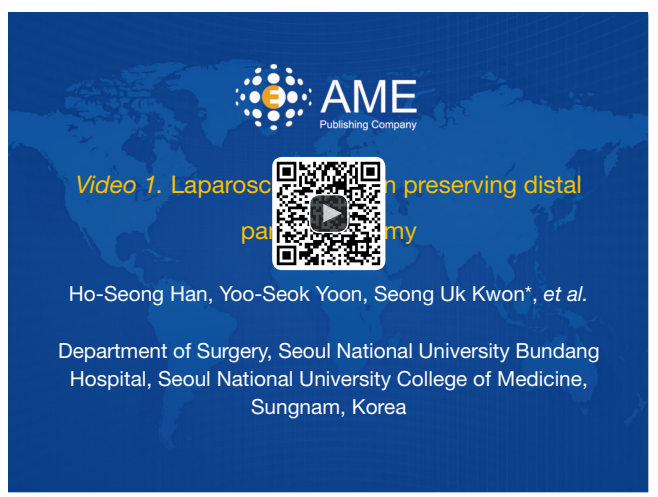

Figure 2 Laparoscopic spleen preserving distal pancreatectomy (14). Available online: http://www.asvide.com/articles/1117

5-mm port is placed at cross point of anterior midclavicular line and left hypochondrium: it is used by the assistant surgeon (Figure 1).

The procedure starts with cutting of greater omentum using an energy device from middle to left until the spleen is exposed. Stomach is retracted cephalad by suturing its posterior wall and pulling out the string using a needle passer. Dissection is then continued at the inferior border of the pancreas. LigaSure is useful to control small vessel by sealing during dissection of pancreas. Medium sized vessels are clipped and divided. LigaSure and the suction tip are useful for dissecting between pancreas and splenic vein (Figure 2).

Then, the dissection is carried on at the superior border of pancreas in order to identify and isolate the splenic artery. After splenic artery isolation, retropancreatic space is made by dissection between pancreas and portal vein. Surgical tape is placed around the pancreas neck and gently lifted upwards by the assistant. Pancreas is transected by The ECHELON FLEX $^{\mathrm{TM}}$ Powered vascular stapler $(60 \mathrm{~mm})$ with Gold cartridge $\left(\right.$ Ethicon $^{\circledR}$ ). The type of cartridge depends on the thickness and texture of the pancreas. Green cartridge is used for thick and hard pancreas or the pancreatic duct can be sutured intracorporeally. Dissection is then carried on from right to left. The LigaSure is frequently used to separate the splenic vessels from pancreatic parenchyma. Gradually, the dissection is continued all the way to the splenic hilum. Meticulous bleeding control and irrigation is done and fibrin glue is applied on the pancreatic resection margin. Specimen is pulled out through extended umbilical port by putting in the vinyl bag. Umbilical port and $10 \mathrm{~mm}$ port site fascia are closed by suture. Drain is placed at the pancreas resection margin through the left $5 \mathrm{~mm}$ port.

\section{Role of team member}

- Dr. Ho-Seong Han: Surgeon;

- Dr. Yoo-Seok Yoon: Surgeon;

- Dr. Seong Uk Kwon: Assistant Surgeon;

- Dr. Hyo Seok Na: anesthesiologist;

- Nr. Yu Jin Heo: scopist.

\section{Tips, tricks and pitfalls}

It is very important to acquire a proper view of the surgical field in laparoscopic surgery. To obtain the right surgical field, the assistant should lift the stomach at the cephalad direction as it interferes with the exposure of the pancreas and the celiac axis. So we have to add an extra port for the assistant to manipulate the stomach beforehand. Hence, if we anchor the stomach by suture and pull the string out of abdomen, the surgical field will remain stable during the whole operation time. If the stomach is large, one or two more sutures will be helpful.

Bleeding from small branches can occur easily while dissecting between the pancreas parenchyma and the splenic vessels. Using the sealing device, it is possible to control these small veins. When clips are used for small veins, it may easily fall off and bleed easily. The sealing device may be useful for secure control of small vessels and shortening operative time. 


\section{Acknowledgements}

None.

\section{Footnote}

Conflicts of Interest: The authors have no conflicts of interest to declare.

\section{References}

1. Iacobone M, Citton M, Nitti D. Laparoscopic distal pancreatectomy: up-to-date and literature review. World J Gastroenterol 2012;18:5329-37.

2. Zureikat AH, Moser AJ, Boone BA, et al. 250 robotic pancreatic resections: safety and feasibility. Ann Surg 2013;258:554-9; discussion 559-62.

3. Borja-Cacho D, Al-Refaie WB, Vickers SM, et al. Laparoscopic distal pancreatectomy. J Am Coll Surg 2009;209:758-65; quiz 800.

4. Kooby DA, Gillespie T, Bentrem D, et al. Left-sided pancreatectomy: a multicenter comparison of laparoscopic and open approaches. Ann Surg 2008;248:438-46.

5. Venkat R, Edil BH, Schulick RD, et al. Laparoscopic distal pancreatectomy is associated with significantly less overall morbidity compared to the open technique: a systematic review and meta-analysis. Ann Surg 2012;255:1048-59.

6. Yoon YS, Lee KH, Han HS, et al. Effects of laparoscopic versus open surgery on splenic vessel patency after spleen

doi: 10.21037/jovs.2016.08.03

Cite this article as: Han HS, Yoon YS, Kwon SU, Cho JY, Choi Y, Jang JS. Laparoscopic spleen preserving distal pancreatectomy. J Vis Surg 2016;2:146. and splenic vessel-preserving distal pancreatectomy: a retrospective multicenter study. Surg Endosc 2015;29:583-8.

7. Carrère N, Abid S, Julio CH, et al. Spleen-preserving distal pancreatectomy with excision of splenic artery and vein: a case-matched comparison with conventional distal pancreatectomy with splenectomy. World J Surg 2007;31:375-82.

8. Shoup M, Brennan MF, McWhite K, et al. The value of splenic preservation with distal pancreatectomy. Arch Surg 2002;137:164-8.

9. Kang CM, Chung YE, Jung MJ, et al. Splenic vein thrombosis and pancreatic fistula after minimally invasive distal pancreatectomy. Br J Surg 2014;101:114-9.

10. Mellemkjaer L, Olsen JH, Linet MS, et al. Cancer risk after splenectomy. Ugeskr Laeger 1995;157:5097-100.

11. Schwarz RE, Harrison LE, Conlon KC, et al. The impact of splenectomy on outcomes after resection of pancreatic adenocarcinoma. J Am Coll Surg 1999;188:516-21.

12. Inoko K, Ebihara Y, Sakamoto K, et al. Strategic Approach to the Splenic Artery in Laparoscopic Spleen-preserving Distal Pancreatectomy. Surg Laparosc Endosc Percutan Tech 2015;25:e122-5.

13. Jean-Philippe Adam, Alexandre Jacquin, Christophe Laurent, et al. Laparoscopic spleen-preserving distal pancreatectomy: splenic vessel preservation compared with the Warshaw technique. JAMA Surg 2013;148:246-52.

14. Han HS, Yoon YS, Kwon SU, et al. Laparoscopic spleen preserving distal pancreatectomy. Asvide 2016;3:348. Available online: http://www.asvide.com/articles/1117 